\title{
Analysis on the Generalization of the Address Term "Teacher" in Chinese from the Perspective of Sociolinguistics
}

\author{
Chenghong You \\ School of Foreign Languages, Polytechnic University, Tianjin, China
}

\begin{abstract}
Teacher" is a respectful form of address towards those who are engaged in education. Under new historical situation, person who is called teacher nearly cover all trades and professions. Teacher is not only an address, which carries professional connotation, but becomes an extensive use of society. In Chinese, the translation equivalent is "laoshi". This paper aims to discuss the developing trends of "teacher" and the reasons of its generalization from the perspective of sociolinguistics.
\end{abstract}

Index Terms - teacher, generalization, phenomenon, reasons

\section{INTRODUCTION}

\section{A. Literature Review}

Address term is one of the most popular topics in Chinese linguistic studies. According to the Chinese Modern Dictionary, address terms is the words used to address somebody in speech or writing. The way in which people address one another usually depends on their age, sex, social group and personal relationship. In some languages, such as Chinese dialects and Japanese, words expressing relationship, e.g. father, aunt, or position, e.g. teacher, lecturer, are used as address terms to show respect and/or signal the formality of the situation, for example, Mandarin Chinese: $b a b a$ qing chi; Japanese: sensei dozo! The address forms of a language are arranged into a complex address system with its own rules which need to be acquired if a person wants to communicate appropriately.

The study of the address term has interested linguistics for some time. Chen (1990) debated the problem of generalization a deficiency of the Chinese address forms in general and broad, but he didn't offer a detail analysis. Address term system mainly includes two aspects in general: kinship address terms and social address terms. The kinship address terms are mainly used between people who keep kinship. The social address terms are applied in the social situations to inflect the relationship between people. (Li, 2004)

"Teacher" is a social address towards those who are engaged in education originally, in Chinese it is pronounced as "laoshi". But the usage of it has experienced overall change in $20^{\text {th }}$ century especially. It is reasonable to say that the research about the address term "teacher" is comparatively rear in current.

The statistical results can be stated in the following table:

\begin{tabular}{|l|l|l|l|l|l|l|l|l|l|l|l|}
\hline Kind year & 2013 & 2012 & 2011 & 2010 & 2009 & 2008 & 2007 & 2006 & 2005 & $\begin{array}{l}2000 \\
\sim 2004\end{array}$ & 2000 \\
\hline Journal papers & 2 & 2 & 2 & 1 & 1 & 1 & & 2 & 2 & & 1 \\
\hline theses & & & 1 & \multicolumn{7}{|c|}{ (Retrieve data from CNKI.) } \\
\hline
\end{tabular}

Analyzing the data in the data base of CNKI, an authoritative and the largest data base in China, we can have a macroscopic view about the status in quo of the research on the address term "teacher". The study of it started in the 1980s. We will find out 16 papers on the specialized study about the address term "teacher" altogether via putting the key words "teacher" "the address term" and "the address term "teacher", in which includes 2 Master theses and 5 journals published on the core journals. The earliest is published in 1988.

Originally, researchers tended to explore the history of the address term "teacher", for instance, how to address a teacher in ancient China and the origin of this name. The representative is Zhen (1989) of Beijing Normal University. He investigated almost the overall cultural and historical literature and dated from the real origin of "teacher". He also explained the variants of the address term in various periods.

Gradually, learners began to pay attention to the evolution and the generalization of the address term. A few of discussion appear on some journals bit by bit. Among these discussions, only 6 papers describe this problem from the point of sociolinguistics and others are concerned with the semantics and word formation. Huang (1988) did a survey about the address term "teacher" used on people who are not real teachers. His project was carried out in the circle of literature and art. So being more accurate, the generalization of the address term "teacher" started from him. When it comes to $21^{\text {st }}$ century, we have to keep a watchful eye on two women Wang E (2005) and Yang Qing (2005). They 
launched a more comprehensive study about the address term "teacher" from the semantics and culture. And they discuss the change of the address term from the perspective of social change, and national address term principle. By contrast with other hot debated issues, the research of the address term "teacher" needs more broadening.

\section{B. Research Question}

The linguistic theory should be used to explain the phenomenon occur in communicate. The paper will explore the reasons of the evolution and the generalization of the address term "teacher" aim at the linguistic phenomenon and describe the variants of the address term and try best to put forward reasonable explanation of the generalization.

\section{A BRIEF INTRODUCTION OF THE HISTORY OF "TEACHER"}

The Chinese term "laoshi" (teacher), as a title for educators, has experienced a long-time development. We first need to look back to the origin of the "teacher". Compared with "laoshi" in modern Chinese, there exists a big difference in grammar between them. In ancient literature, Lao has its real meaning, while in modern Chinese; Lao carries no real meaning, only a prefix. That is to say, "lao" and "shi" were two separated words. "lao" meant seniors and "shi" refered to the people who conveyed knowledge to others. These two words were used together in the Mencius for the first time (Xu, 2011). In the Confucian literature before the Tang and Song Dynasties (before 618 A.D.), "laoshi" corresponded to Daru, Suoru, meaningdgreat man of learningd. In Tang Dynasty, "laoshi" indicated monks. In the the Five Dynasties, "laoshi" was the address term of craftsperson. From now then, "laoshi" contained the meaning of respect. In Jin Dynasty, the meaning of "laoshi" was close to the modern usage, it referred to the person who taught students. In the Tang and Song Dynasties, "laoshi", as a religious term either in Taoism or Buddhism usually referred to preachers instead of worldly educators. After the Reign of Jiajing in the Ming Dynasty, influenced by the imperial examination system, "laoshi" evolved into an honorable title used by the disciples on their masters. (Tian\&Zhang, 2007) At that time, "laoshi" was used to address the examiners in imperial competitive examination, and it was only limited to the examinees. Within the next 300 or 400 years, "laoshi" gradually changed into an honorable title used by common students to refer to their teachers. In the 20th century, with the surging of the modern schools and the abolition of the imperial examination system, the title "laoshi" finally lost its connection with the imperial examination system. It is after the founding of the People's Republic of China that "laoshi" has really become a popular honorable title for common educators. In 1940s, "laoshi" first popularized in elementary and secondary schools, which indicating the respect towards teachers. Until the middle of 1950s, it became fashionable in colleges gradually instead of "xiansheng". But in the 1960s and 1970s, it was forced to be abolished for some political reasons. It was desterilize from the late 1970s.

Nowadays, "laoshi" as a title for educators embodies rich traditional cultural connotations. It not only displays the professional identity of the teachers properly, but expresses the esteem and expectation of the society towards teachers' morality and integrity.

\section{GENERALIZATION}

The term generalization is widely used by linguists in the second language acquisition. It can also be used in another way sociolinguistics to refer to the language use.

\section{A. Definition of Generalization}

It may be helpful at this point to define the term "generalization". Here, it means that different form of address has different manifestation according to certain context. The generalization of the social address term refers to the phenomenon that the address form reflecting some social relationship "incorrectly" used on some occasions. Those occasions do not manifest the relationship the address represents. It could be regarded as the variants of "laoshi" according to various situations.

For instance, "laoshi" belongs to the category of social address term, and it implies the character of "conveying knowledge and educating students". While in some cases, "laoshi" has become a common term. Engineers, doctors, actors and lawers all can be called "laoshi" in daily life. However, some people who don not work on the career of education are called "laoshi" currently. This phenomenon is what we called "generalization". In fact, generalization has been a growing feature of the address term of "laoshi" in Chinese.

\section{B. Generalization of "Laoshi" in Chinese}

Through the previous state, we know about the evolution of the address term of "laoshi" from ancient to modern. It is not to say that it has come to an end. At present, the meaning and usage of "laoshi" is still experiencing subtle changing in language use. It has exceeded the traditional limit of fields and boundary. It is no longer used to show the fixed career, identity or profession. This term has been popular and generalized in many social situations. There are some occasions we are familiar with.

1. "Laoshi" Used on the Campus

Teacher is the person who teaches students the knowledge, tells students the way to live and answers students' questions. It is suitable for us to call the person "laoshi" who working as a teacher. But what deserves our attention is 
that, we may call the other employers "laoshi" on the campus in daily life. There are a lot of sections in a school in addition to teaching section, such as logistics department, administrative department and security section. We are used to calling the title of the staff for administrators for their status; but have no idea of their titles; we have to give them the title of "laoshi" as insurance. As for the staff for logistics, like the librarians and security guards, we call them "laoshi" or "shifu" maybe for politeness. To sum up, almost all of the staff on the campus can be titled as "laoshi". This phenomenon can be categorized into the generalization of "laoshi".

Zhu (2009) did a detail survey in a university in Beijing, aiming for probe in the generalization of "laoshi" in college. She interviewed 100 students and distributed 100 questionnaires to the college students. The result manifested that $72.2 \%$ of students called "laoshi" to the administrators in schools, and $46.9 \%$ of students called "laoshi" to the staff in logistics department. Also, 61.9\% of students still use the term "laoshi" without knowing the other's occupation.

2. "Laoshi" Used on the Teachers' Relatives

There is no appreciate address term for the teachers' husband or wife in Chinese. When it comes to a male teacher's wife, the students may call her "shimu" in Chinese. But what should the students call for the female teacher's husband? There is no corresponding address term. In order to avoid of embarrassment, we students have to borrow the female teacher' identity and call her husband "laoshi" uniformly, even if he may not be a teacher. It becomes necessary for students to choose the term. The choice is a matter of remedy. It is difficult to put forward an ideal answer. Maybe some people think of “shizhang(师丈)” or “shigong(师公)”, but they hear so weird in Chinese. Also, we do not use this kind of expression in daily communication. This kind of generalization can be categorized as compensation to the deficiency of the address term system.

3. "Laoshi”" Used in the Cultural Knowledge Fields

As an address term "laoshi" is not only applied in the educational fields, but also in some other cultural knowledge fields.

Huang (1988) did a famous survey in Beijing. The survey aimed at the term "laoshi" used in various domains in spoken language. It was in the form of questionnaire and interview by quantitative research and qualitative research. He interviewed and surveyed totally 50 people involved 5 fields and 12 sections. The five fields included the circle of literature and art, the circle of press, the circle of radio and television, the circle of publish and the circle of sports. His report inevitably mirrored the facts from two angles. Internally, besides the education area, "laoshi" was widely used in the above five areas to varying degrees. The address term "laoshi" was spreading to various kinds of contexts gradually. Externally, an interest result, "laoshi" was utilized in the circle of literature and art most frequently, with the percent of 80. The rate decreased with the circle being further to the circle of literature and art. The author guessed it was due to the social statue of the showfolk. This conclusion may seem very satisfactory, since it is object and the results conform to the popular psychology. Nevertheless, this may require extra linguistic viewpoints to add to the explanation.

4. "Laoshi" Used in other Social Occasions

As the language varies, the term "laoshi" has gradually lost the original meaning of "teaching feature". It is often seen, some doctors in the hospital call their colleagues as "laoshi", no matter they are equal in the position or not. The appellation "laoshi" is such an adaptable title that will not cause any offence. Similarly, we sometimes hear hairdressers call their colleagues "laoshi" as well. Likewise, we can see the young actors or the audience call the old actors "laoshi" in the TV shows. It's the same to the experts who are always called "laoshi" by others. Still, people from different business also choose "laoshi" to greet each other, even if they have no disparity in both age and qualifications. For example, when a businessman greets an intellectual, he would tend to call the opposite "laoshi" (Wang \& Yang, 2005). On one hand, this can be attributed to the semantic vagueness of the word "laoshi" as some researcher's state. On the other hand, this phenomenon roots in the diversification of professions which are more or less share certain similarity to teaching job.

\section{THE REASONS OF THE GENERALIZATION}

if we look at what is involved in addressing another, it seems that a variety of social factors usually governs our choice of term: the particular occasion; the social status or rank of the other; sex; age; family relationship; occupational hierarchy; transactional status (.i.e. a service encounter, or a doctor-patient relationship, or one of priest- penitent); race or degree of intimacy (Wardhaugh, 2000).

\section{A. The Aspect of Politeness}

Through the choice of promoninal forms and address terms, we can show our feeling toward others-solidarity, power, distance, respect, intimacy, and so on-and our awareness of social customs. Such awareness is also shown though the general politeness with which we use language. Politeness itself is socially prescribed. The concept of "politeness" owes a great deal to Goffman's original work on "face". In discussing "politeness", the concept of interest to them, Brown\& Levinson (1987) define face as the "public self-image that every member wants to claim for himself". They also distinguish between positive face and negative face. Positive face is the desire to gain the approval of others. The positive consistent self-image or "personality"...claimed by interactants. Negative face is the desire to unimpede by others in one's action, "the basic claim to territories, personal preserves, rights to non-distraction...freedom of action and freedom from imposition. Positive face looks for solidarity; negative face, however, is more problematic for it 
requires interactants to recognize each other's negative, .i.e. the need to act without giving offence. (Wardhaugh, 2000)

Politeness is treated as the strategy to saving face (face-saving strategy) in communicate. The one with high solidarity has more freedom in choosing the address terms. While, for the one with low solidarity, one has to consider the face of the opposite. The address term should maintain the positive face and the negative face at the same time. In the light of this theory, "laoshi" seems the best one to title some seniors. For example, audience can call a host "teacher"; an actor can call another actor as "laoshi". The address "laoshi" has the denotation of pundit and decency, so "laoshi" conveys the respect toward others on some level, which maintains their faces. Beyond that, "laoshi" itself possesses a sort of intimacy, which is good to remove the feeling of strange.

\section{B. The Aspect of Power and Solidarity}

"Power" is self-explanatory, but solidarity is harder to define. It concerns the social distance between people-how much experience they have shared, how much social characteristics they share (religion, rare, occupation, interest, etc.), how far they are prepared to share imtimacies and other factors. Although individuals perform different tasks and often have different values and interest, the order and very solidarity of society depends on their reliance on each other to perform their specified tasks (Hudson, 2000). Choosing the right terms of address to use in a hierarchical organization may not always be easy. How does one decide to choose the address term, it must refer to both power and solidarity.

From the history of "laoshi", in Chinese, "laoshi" is an address term with more power and social position. On the on hand, when we need to address a person with more power, "laoshi" is full of commendatory and it reflects the distinction between each other. On the other hand, people tend to give the other more power in the communication for politeness or praise even if they are equal in social position. Of course, the praised one should be somewhat accomplished in certain area or has some power, or it would be a more or less ridiculous and flattering. For instance, staffs in school, besides the teachers, own more power in the eyes of students, such as the administrators, who are in charge of the students' issues. But, it seems that few of students may address "teacher" to a cleaner in the school. The achievement matters are always reflected in the relationship between junior and senior in other businesses like doctors and engineers. They are skilled and specialized in their own area, so others give them the title of "laoshi". At the same time, there will be high solidarity between the speaker and hearer if "laoshi" is used.

One interesting hypothesis about address terms (Robinson, 1972) is that, in those society in which a person's status derives from his or her achievements, few distinctions in address are made.

\section{The Aspect of Culture and Language}

The relationship between language and culture is deeply rooted. Language is used to maintain and convey culture and cultural ties. Different ideas stem from differing language use within one's culture and the whole intertwining of these relationships start at one's birth (Hudson, 2000).

We all know culture is the kind of knowledge which we learn from other people, either by direct instruction or by watching their behaviors. Since we learn culture from those around us, we may assume that we share it with them, and in particular when we use language.

China is a country with an ancient civilization of five thousand years. Especially the Confucian School with its wide and expert connotation of thought is greatly worshiped by Cater generations. In ancient China, people treat etiquette as the most important part of the culture. The obsession of hierarchy: monarch-subject relationship and father-son relationship are the core concept of the etiquette. Under the influence of the strict feudal hierarchy order and high ethical and moral standards, people pursuit the ethical morality of respect for seniority. "Laoshi" is the ones who have the knowledgeable merit and impart knowledge to commons. It stands to reason that "laoshi" is a high-ranking role and they should be admired by others. Moreover, as the old saying goes, "a teacher of one day is a father of a lifetime", so the address "laoshi" has an unshakable position in the tradition thought.

In modern China, although the feudal hierarchy order has been abolished thoroughly, the "brand" of culture is remained. In addition, education is becoming important increasingly. The title of "laoshi" is endowed with new connotation and sense, especially many metaphors. For example, "Teachers are engineers of human soul".

Gradually, the meaning of "laoshi" extends more widely. It can be used to the person who has some influence on us or the idols in our minds. From this angel, we may understand why the actors are called "laoshi" by people.

\section{The Aspect of Context}

Language is a social fact. A social context is a semiotic structure which we may interpret in terms of three variables: a "field" of social process (what is going on), a "tenor" of social relationships (who are taking part), and a "mode" of symbolic interaction (how are the meaning exchanged). So field refers to the situational setting in which a piece of language occurs, and embraces not only the subject-matter in hand but the whole activity of the speaker or participant in a setting. Tenor refers to the relationship between participants, not merely variation in formality, but, such question as the permanence or otherwise of the relationship and the degree of emotional charge in it. Mode refers to the channel of communication adopted: not only the choice between spoken and written medium, but much more detailed choices. Firth thinks that the context corresponds more or less to what sociologists would regard as the status and role of the participants.

Address terms are chosen in the limit of the context. Some social contexts operate the pattern of address terms. 
However, the social context is so flexible that the language system may disable to deal with the changes. But one must keep sure that the language in communicate should be tact and appropriate, which make the hearer feel comfortable. Then, the language with semantic vagueness may be the best alternative.

In some cases, the social context is easy to distinguish and we can give out a correct response rapidly. (Zhou, 2013) For example, when a student meets his teacher on the campus, he can call the teacher "laoshi" without hesitation. There is nothing to be said against it. But when the student is in the library and need help of the librarian, he is not able to give the librarian a reasonable title. Then, "laoshi" is the idea most insurance. In other cases, the social context is so complicate recognize and we disable to reply the dilemma. For example, when a lot of participants in various grades and ranks are on the spot, there needs a skill to save faces especially the faces of the lower ranks'. We should not use the address terms with clear marks. Here, "laoshi" is a gentle and neutral term. It expresses the feeling of admire and gives the hearers equal positions, which can make the conversation tact and smoothly.

\section{E. The Deficiency of the Address Terms}

It is necessary to give a definition of deficiency. A simple stated was given by Chen Jianmin in 1990. "As the society develops and the concept updated, there will be a lack of tact and exact address terms in certain social occasions. This leads to the problem of the deficiency of the address terms." (Chen, 1990)

In societies which claim to be egalitarian there may be some doubt as to what is the appropriate address term, and consequently none at all may be used between, say, in English, husband and wife' mother; son who is learning a lowly job in a company and father who is the company president; police officer and young male offender; and older male and much younger feminist (Hudson, 2000). In Chinese, how to address a female teacher's husband? One consequence is that choosing the right terms of address to use in a hierarchical organization may not so easy.

Nowadays, people's social circles are expanding little by little. In some cases, people have to confront more strangers. That is to say, people need to address those beyond relatives. A whole society which is undergoing social changing is also likely to show certain indications of such change if the language in use in that society has a complex system of address (Hudson, 2000). How to choose a suitable address needs to think twice. On the short view, "xiansheng" and "xiaojie" is the commonest used addresses. But these two words are too formal to use in the daily life, because they are fit for the formal situations like business and conference. Their usage is toughly limited.

\section{HYPOTHESIS}

The address "laoshi" has burst the restraints of campus and its scope of application is spreading rapidly. There is no exaggeration to say that there is trend for it to transform to a phatic expression. For example, it is widely used in some area in Shandong province when someone needs to ask for help from a stranger or to greet others. It conforms to the modernists' social psychological of emotional and practical. And so on, "laoshi" will be more popular in the future via the semantic generation. Of course, this is just a hypothesis.

\section{CONCLUSION}

Our goal of this paper was to investigate the manifestations and social reasons of the generalization of the address term "laoshi". We looked back to the evolution process of the term and illustrate various cases of its generalization. The key point is to explore the reasons in the perspective of sociolinguistics. In the end, we put up with a hypothesis that the address "laoshi" may become a phatic expression by the above analysis. This is just a problem of time to judge its rationality. It must remain to be seen and practiced.

As we all know, in Chinese, some addresses like "laoban" and "lingdao" are usually used to address the people who are not a boss or a leader. This is the phenomenon of generalization. But no matter the speaker or the hearer will not take it seriously. However, when it comes to "laoshi", the core meaning is maintained in the address, it contains the meaning of respect, power, politeness or order more or less. This makes the generalization of "laoshi" deserves more study of researchers.

Nevertheless, the generalization should cause us to ponder the linguistics phenomenon. That is the generalization needs to be standardization in the process. It is not necessary a good thing to use the address at will. At least, the core meaning of respect and admired should be remained. Otherwise, the generalization may change degenerated to abasement. Therefore, we must be cautious about the generalization phenomenon. That is to say the reasonable should be encouraged and the irrational should be impeded.

\section{REFERENCES}

[1] Brown. P. \&S. Levinson. (1987). Politeness: Some Universals of Language Use. Cambridge: Cambridge University Press.

[2] Chen Jianmin. (1990).the Generalization and Lack of the Appellation of Modern Chinese. Chinese Language Learning, 1, 20-24.

[3] Huang Nansong. (1988). the Social Survey on the Title Laoshi. Language Teaching and Linguistic Studies, 4, $108-112$.

[4] Hudson, R.A. (2000). Sociolinguistics. Beijing: Foreign Language Teaching and Research Press.

[5] Li Shuxin. (2004). On Two Major Principles of Address Terms. Journal of Mongolia University (humanities and social sciences), 5, 77-82. 
[6] Robinson, W.P. (1972). Language and Social Behavior. Harmondsworth, England: Penguin Books.

[7] Tian Zhengping \&Zhang Xiaoqian. (2007). On the Original and Development of the Title Laosho (Teacher). Journal of Zhejiang university (humanities and social sciences), 3,62-67.

[8] Wang E \&Yang Qing. (2005). the Historical Change of the Address Term of "Teacher". Inner Mongolia Social Sciences, 5, 93-96.

[9] Wardhaugh, R. (2000). an Introduction to Sociolinguistics. Beijing: Foreign Language Teaching and Research Press.

[10] Xu Yuman. (2011), the Research of the Appellation "Teacher". M.A. Thesis. Hubei University.

[11] Zhen Yuegang. (1989). the Research of the Title Laoshi in Ancient China. Journal of Beijing Normal University (social and sciences), 4, 54-62.

[12] Zhou Ying. (2013). the Research for the Extensive Use of "Teacher" from the Perspective of Sociolinguistics. Modern Marketing Journal, 3, 298-299.

[13] Zhu Yan. (2009). the Appellation of Teacher on the Campus. Journal of Chifeng University, 8, 190-192.

Chenghong You was born in Jinzhong, China in 1988. She received her Bachelor degree in English linguistics and literature from Taiyuan Normal University, China in 2011.

She is currently a postgraduate in the School of Foreign Languages, Polytechnic University, Tianjin, China. Her research interests include foreign languages and applied linguistics. 